\title{
Ambulation using the reciprocating gait orthosis and functional electrical stimulation
}

\author{
E. Isakov MD ${ }^{1} \mathrm{R}$. Douglas $\mathrm{PhD},{ }^{2} \mathrm{P}$. Berns $\mathrm{MD}^{2}$ \\ ${ }^{1}$ Biomechanics Laboratory, Loewenstein Rehabilitation Hospital, Ra'anana, Israel, \\ ${ }^{2}$ Doctors Medical Group, Beverly Hills, California, USA.
}

\begin{abstract}
Until recently, rehabilitation engineering offered 2 different methods to improve daily living independence for spinal cord paralyzed subjects. One, the use of various orthotics and the other, the application of functional electrical stimulation. In the present work we chose to combine reciprocating gait orthosis (RGO) with functional electrical stimulation (FES) into one hybrid system. A detailed biomechanical and clinical instruction for the use of this system is given. Results obtained from application of the hybrid system on a complete T4 paraplegic patient demonstrate that the most significant contribution was the reduced invested energy cost required for standup and for ambulation.
\end{abstract}

Key words: reciprocating gait orthosis; functional electrical stimulation; hybrid system; paraplegia; paraplegic locomotion.

\section{Introduction}

Spinal cord trauma or disease may result in an incomplete or complete active functional inability to stand up and to walk. As a result, spinal cord injured (SCI) patients are destined to a wheelchair for the rest of their lives. Paraplegics and quadriplegics, more than any other group of invalids, are forced into a very long period of hospitalization for rehabilitation purposes. One of the main goals in the rehabilitation of SCI patients is to enable the patient to stand and walk. Until recently, the only way of helping these patients to reach these aims was by fitting them with conventional long leg braces. However these braces are heavy and cumbersome and many patients stop using them soon after discharge from hospital. ${ }^{1.2}$ Furthermore, only incomplete low level paraplegics may benefit and then to a limited extent only from such braces. All others find the wheelchair more practical as it requires a smaller energy demand for daily mobilization. ${ }^{3,4}$

During the last 2 decades, researchers have been trying to challenge the SCI invalidity by investigating rehabilitation engineering. Efforts have been invested in 2 different directions: the first, improvement of conventional long leg braces $;^{5-7}$ and the second, through the application of electrical stimulation for functional activation of the lower limb muscles via implantable ${ }^{8,9}$ and surface electrodes. ${ }^{10}$

Important contributions in the field of orthosis were accomplished through the development of the hip guidance orthosis (HGO) ${ }^{11}$ and the reciprocating gait orthosis (RGO). ${ }^{12,13}$ These custom-made braces enable SCI patients to reach functional standing and efficient ambulation. ${ }^{14,15}$ The other field of interest lies in the use of FES for these SCI patients. The Loewenstein Biomechanics Laboratory group has been conducting an intensive research program into FES for the last 8 years, and have evaluated the influence of FES on different physiological systems ${ }^{16}$ and the biomechanical aspects of standing and walking by means of FES. ${ }^{17}$ However, in spite of international efforts, success is still limited and only few paraplegics are able to stand up and walk by means of FES only. FES can only be used by very fit, young, low level spastic paraplegics. Although some paraplegics gained the capacity to walk, they were able to do so for only short distances and mainly within the laboratory environment. ${ }^{10}$

In the present work we have combined FES with RGO into a hybrid system. Our 
clinical approach together with the technical explanation of the system are fully described. The quality of the ability to stand up and sit down as well as to walk, related to the level of physical effort used, was investigated.

\section{The biomechanical principles of the hybrid system}

To understand the concept of the hybrid system we will first discuss the biomechanical principles of the RGO system. ${ }^{12}$ The existence of a solid ankle-foot orthosis (AFO), positioned in approximately $7 \mathrm{de}$ grees of plantar flexion, assists in raising the body center of gravity during heel-off through toe-off phases. As a result, no lateral trunk shift is required for the ground clear-off of the swing leg (Fig 1). The custom molded plastic pelvic girdle ${ }^{18}$ serves as a lever when the subject is pushing his braced trunk backwards to generate extension of the hip joints. In fact, the brace hip joints permit a range of motion of approximately 15 degrees extension and 45 degrees flexion. Then, during ambulation, when the patient shifts his weight on to the forward stance leg and pushes his upper trunk backwards, the Bowden cable system of the RGO is being activated. This dual cable system, attached to both hip joints of the brace provides a push-pull type of mechanism. An extension in the brace hip joint of

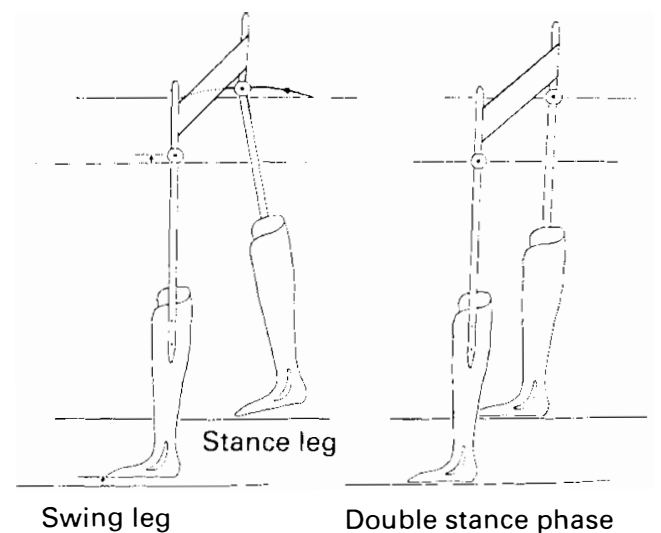

Figure 1 Upward shift of the RGO during the heel-off phase. the stance leg brings the cable into a state of tension. This mechanical energy is being transferred to the opposite brace hip joint and as a result it pulls forward into flexion the swinging contralateral limb (Fig 2). Therefore, the prime mover of the RGO system is the hip extension movement of the stance limb which results in propulsive hip flexion of the contralateral swing leg. On the other hand, to stand up by wearing the RGO alone, the knee brace joints have to be locked, the legs are extended forward and the subject is required to pull and push his entire body weight over the walker.

Standing up and sitting down by means of FES only is achieved by stimulation of the gluteus maximus and quadriceps muscles of both legs. By combining FES with the RGO system we add some important biomechanical advantages for standing and walking. Using both systems concurrently the subject can sit on the edge of a chair with the RGO hip and knee joints unlocked and at the moment the current is turned on, the subject is raised to the upright position by the force of the contracting quadriceps and glutei, using the walker to maintain equilibrium only.

Furthermore, in ambulation using the RGO only, extension of the stance hip joint is being achieved passively by shifting the upper trunk backwards while the hip flexion of the swinging opposite leg is a subsequent product of this movement. Adding FES to the muscles involved in generating these

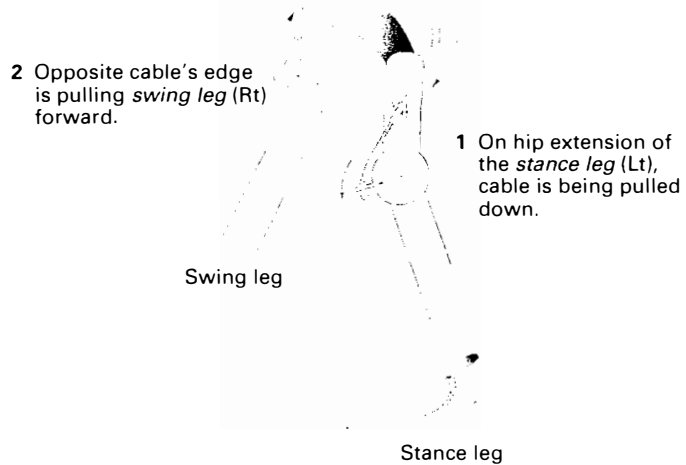

Figure 2 A schematic description of the cable's reciprocate functions. 
movements will assist the subject to benefit from the RGO system (Fig 3). A strong contraction of the gluteus maximus muscle of the stance leg will assist in getting the desired hip extension and, contemporaneously, the contraction of the rectus femoris of the opposite leg provides assistance to the pulling cable which promotes hip flexion of the swing leg.

\section{Equipment}

For FES application we used the Loewenstein modified Mark 1 stimulator. The characteristics of the stimulator are detailed in Table I. The stimulator contains 3 different operating programs addressed for exercising, standing and walking. Two external switches provide a manual command. These switches are attached to both walker hand-
Table I Stimulator characteristics

\begin{tabular}{|c|c|c|}
\hline Pulse rate & $24 \mathrm{~Hz}$ & (unadjustable) \\
\hline Pulse width & $250 \mu \mathrm{sec}$ & (unadjustable) \\
\hline Pulse amplitude & $0-250 \mathrm{~mA}$ & (adjustable) \\
\hline Pulse shape & asymmetric, & biphasic \\
\hline Output & $0-200$ volts & \\
\hline Channels & 6 & \\
\hline Programs & $\begin{array}{l}\text { exercising } \\
\text { stand-up } \\
\text { walking }\end{array}$ & $\begin{array}{c}\text { (automatic) } \\
\text { (automatic) } \\
\text { (manual) }\end{array}$ \\
\hline Power source & $\begin{array}{l}10 \times 1.2 \mathrm{~V} \\
\text { rechargeab }\end{array}$ & ad batteries, \\
\hline
\end{tabular}

External switches 2

les (Fig 4) and serve for stand-up, sit-down and ambulation programs. The small size stimulator can be attached either to the subject's belt or to the walker itself.

We used 'Uni Patch', reusable free form

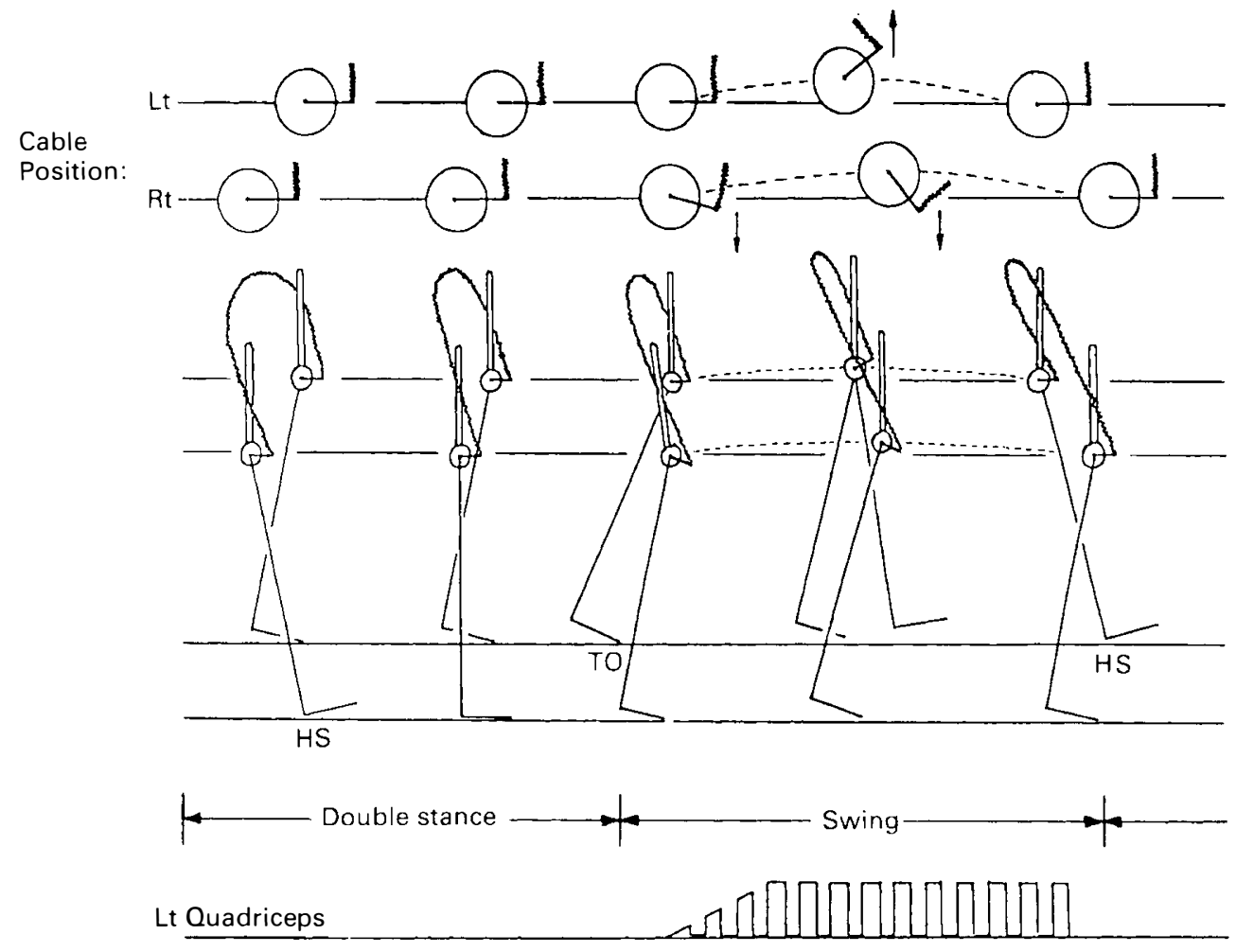

FES

Sequence:

Rt $\frac{\text { Gluteus \& }}{\text { Hamstrings }}$

Figure 3 A schematic illustration of the relationship between the RGO and FES in the hybrid system. 


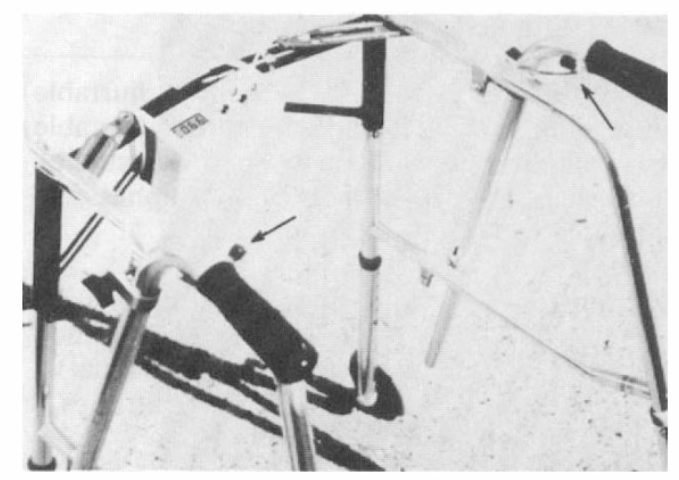

Figure 4 The FES external knobs attached to the walker handles.

electrodes, constructed from blended polyester and containing a hypoallergenic solid gel. These are self adherent and do not necessitate the use of ulterior skin fixation.

The heart rate was monitored every 6 seconds using Ohmeda Biox 3760 Pulse Oximeter (pulse rate accuracy $\pm 1.7 \%$ ).

\section{Method}

A 40 year old woman, with a complete T4 level paraplegia, was chosen for the present work (Table II). She was fitted with the RGO 2 years earlier and since then was ambulating outdoors for approximately 2 hours each session, at least 4 times a week. She gained the ability to walk uninterruptedly with the help of a walker for a distance of about $1.5 \mathrm{~km}$.

The first 3-4 weeks of FES application were concentrated on strengthening the quadriceps and gluteus maximus muscles. The quadriceps were exercised isotonically to produce knee extension in the sitting

Table II Subject characteristics

\begin{tabular}{ll}
\hline Sex & $:$ Female \\
Age & $: 40$ \\
Date of injury & $: 1.11 .1985$ \\
Level of injury & $:$ T4-5, \# dislocation \\
Surgery & $: 2$ Harrington rods \\
Relevant neurological findings: \\
\\
Sensory $\quad$ T4 level \\
Motor $=$ T4 complete \\
Tone $\quad=$ Spasticity \\
\hline
\end{tabular}

position. Initially, the knees were extended against gravitation only and later on weights were placed around the ankles, thereby increasing the resistance to the contracting muscle and improving the strengthening effect. The gluteus maximus muscles were trained isometrically with the subject lying face down.

Following the strengthening stage the subject was trained to operate the hybrid system for stand-up and walking. During the stand-up procedure, before the application of the RGO, a pair of electrodes was applied to the left and right gluteus maximus and quadriceps muscles, and the stimulator was adjusted to the stand-up program which allowed a simultaneous stimulation of all 4 muscles. The subject sat on the edge of the chair using her RGO with the hip and knee joints unlocked. The level of impulse amplitude necessary to generate a strong enough contraction of the involved muscles was adjusted at this stage; then she leaned forward towards the walker, shifting her center of gravity over her knees. By pressing both handle knobs simultaneously the gluteus maximus and quadriceps muscle were stimulated and contracted bilaterally. The contraction of these main lower limb extensors raised her to an upright position. When she stood up, she locked both brace knee joints by pushing her knees backwards and the brace hip joints by pushing her pelvis forward. At that moment, being fully supported by the RGO, she unlocked the brace joints and releasing the handle knobs she lowered herself gradually on to the chair under the control of the relaxing muscles. During the reciprocating gait procedure the stimulator was adjusted to the reciprocating gait program with the level of impulse amplitude approximately the same as for standing up. In the ambulation program an alternate function of the handle knobs was allowed. Whenever one of the handle knobs was pressed by the subject, the gluteus maximus on one side and the quadriceps of the opposite leg were activated simultaneously. The contraction of the gluteus provided the desired hip extension which pulled the anterior cable into tension. The tensed cable pulled upward the opposite brace hip joint while the contracting rectus femoris of 
the same hip assisted the swing leg to move forward and to generate a step. At this stage the pressed knob was released and the subject was able to press the other knob to initiate another step. Each test was performed 5 times, and the results obtained indicate the average values of these trials.

\section{Evaluation}

It has been shown that oxygen consumption and heart rate are linearly related at submaximal effort. ${ }^{19}$ Physical effort, such as walking, can be assessed and graded by means of the oxygen consumption ${ }^{20}$ or physiologocal cost index (PCI). ${ }^{21,22}$ It has also been documented that in subjects with complete SCI below level T3, oxygen uptake and heart rate are linearly related. ${ }^{23}$ Therefore we found PCI suitable in order to evaluate performance of walking in our D4 level subject:

$$
\operatorname{PCI}(\mathrm{bts} / \mathrm{m})=\frac{\begin{array}{c}
\text { walking heart rate }- \\
\text { rest heart rate }(\mathrm{bts} / \mathrm{min})
\end{array}}{\text { walking speed }(\mathrm{m} / \mathrm{min})}
$$

For the evaluation of the quality of gait the subject was asked to walk along a $100 \mathrm{~m}$ asphalted outdoor path. One test was performed using the RGO and the second test using the hybrid system. Gait analysis for step length, step time and gait velocity was studied. These parameters were calculated through the measured overall distance time, and the computed number of steps for the given distance.

The ability of the subject to stand up using RGO only, and RGO combined with FES was evaluated simply by counting the number of times the patient was able to stand up and sit down repeatedly over a 2 minute period.

The resting heart rate was monitored before each test and at 6 second intervals during the test. The subject was allowed to rest for 30 minutes between each trial. The trials sequence was chosen randomly.

\section{Results}

The results for each of the described standup and walking tests using the RGO only and the hybrid system are compared. Results obtained using the FES only have been published previously. ${ }^{16}$ Gait analysis and PCI results are detailed in Table III. Using the hybrid system the number of steps taken per minute was greater $(42 / \mathrm{min})$, steps were shorter $(0.59 \mathrm{~m})$ and a higher velocity of gait $(25.2 \mathrm{~m} / \mathrm{min})$ attained. The use of the RGO only for walking demanded an increase of 61 beats per minute (bts/min) as compared to $39 \mathrm{bts} / \mathrm{min}$ when using the hybrid system. PCI was found to be 2.55 and $1.54 \mathrm{bts} / \mathrm{min}$ for the RGO and the hybrid system respectively.

In the course of 2 minutes the patient was able to repeat the stand-up and sit-down procedure 6 times using the RGO and 14 times when using the entire hybrid system. The effort required for stand-up and sitdown caused an increase in heart rate of 55 and $30 \mathrm{bts} / \mathrm{min}$ when using the RGO and the hybrid system respectively.

\section{Discussion}

The concept of combining orthotics together with FES was first described in $1972 .{ }^{24}$ Since then, investigators have evaluated the advantages of different hybrid systems. Functions such as standing up and sitting down as well as ambulation become more efficient and require less energy consumption when combining FES with $\mathrm{HGO}^{25}$ or with RGO. ${ }^{26,27}$

In the present work we describe our approach using a hybrid system combining RGO and FES, and give details of clinical and technical principles for this combination. To evaluate the efficacy of this method we chose a complete T4 paraplegic subject, who was evaluated performing the tasks of stand-up and sit-down as well as

Table III Gait analysis

\begin{tabular}{lccc}
\hline Parameter & RGO & $\begin{array}{c}\text { Hybrid } \\
\text { system }\end{array}$ & FES $^{*}$ \\
\hline Cadence (/min) & 39 & 42 & 20 \\
Step length (m) & 0.61 & 0.59 & 0.31 \\
Speed (m/min) & 23.9 & 25.2 & 6.2 \\
\hline
\end{tabular}

${ }^{*}$ Results published by Isakov et al ${ }^{16}$ 
ambulation. The results obtained with the hybrid system were compared with those obtained with the RGO only (Table III). Although influences of the hybrid system on speed of gait was small, the reduction in effort demand was found to be impressive. Values of PCI during walking for normal subjects range between 0.11 to $0.51 \mathrm{bts} / \mathrm{min} .{ }^{21}$ In our subject a reduction of PCI from $2.55 \mathrm{bts} / \mathrm{min}$ with the RGO only, to $1.54 \mathrm{bts} / \mathrm{min}$ with the hybrid system, proves the efficacy of using this proposed hybrid system.

Stand-up and sit-down have been found to be much easier using the hybrid system, and the results indicate that this system enables a higher number of repetitions in 2 minutes and a smaller demand in effort as there is a much smaller increase in heart rate. Subjective reports from the patient indicate that she was able to control her steps better under the influence of the hybrid system, and she also felt comfortable and less tired when using it. We would like to recommend the use of hybrid system in SCI subjects suffering from a lesion above T12. An already trained RGO walker might need some 4-8 weeks for FES training and this will enable him to use the hybrid system correctly at a later date for stand-up (Figs 5,6) and ambulation (Fig 7).

We also wish to stress that subjects using the hybrid system will benefit from the well known advantages connected with the daily use of FES treatment such as a reduction in spasticity, ${ }^{26}$ prevention of osteoporosis, ${ }^{28}$

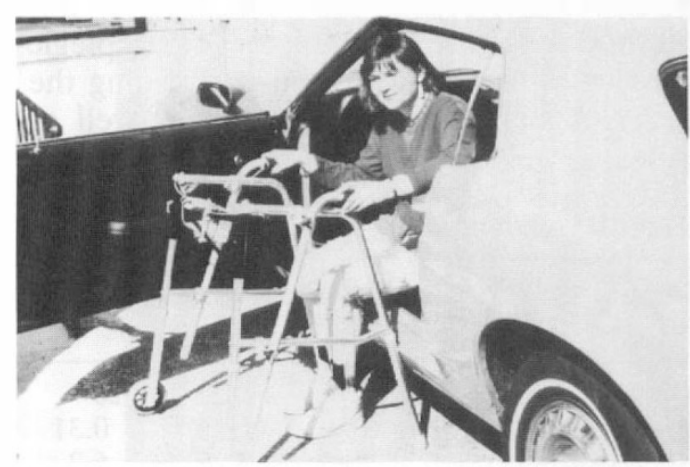

Figure 5 Subject is sitting in her car ready to stand up. improvement in blood circulation, ${ }^{29}$ and finally, improvement in physical fitness. ${ }^{16}$

\section{Acknowledgement}

The authors would like to thank Dr A Korzets for his willing assistance in the phrasing of the manuscript.

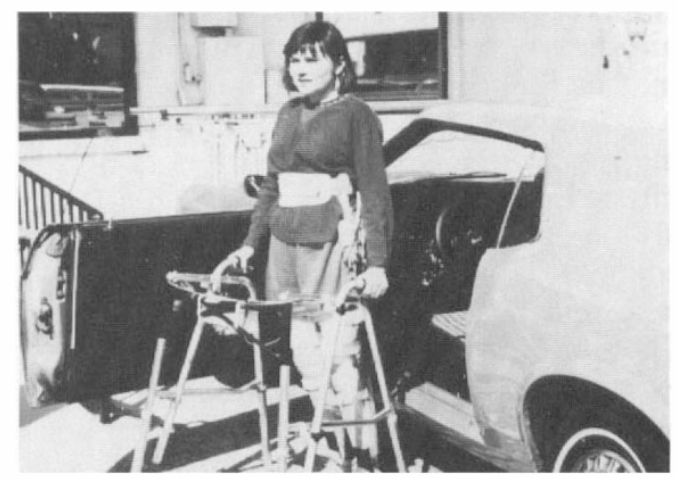

Figure 6 Subject standing up by means of the hybrid system.

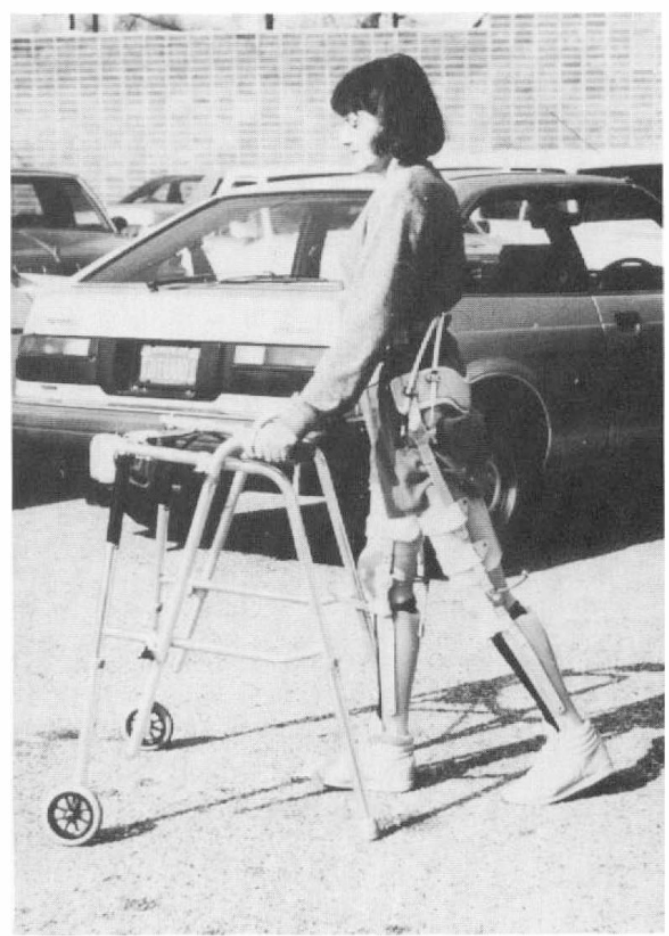

Figure 7 Subject is walking outdoors by means of the hybrid system. 


\section{References}

1 Rosman N, Spira E (1974) Paraplegic use of walking braces: a survey. Arch Phys Med Rehabil 55: 310-314.

2 Coghlan JK, Robinson CE, Newmarch B, Jackson G (1980) Lower extremity bracing in paraplegia. A follow-up study. Paraplegia 18: 25-32.

3 Milkelberg R, Reid S (1981) Spinal cord lesions and lower extremity bracing: an overview and follow-up study. Paraplegia 19: 379-385.

4 Heinemann AW, Magiera-Planey R, Schiro-Geist C, Gimines G (1987) Mobility for persons with spinal cord injury: an evaluation of two systems. Arch Phys Med Rehabil 68: 90-93.

5 Henshaw JT (1979-80) 'Walking' appliances for paraplegics and tetraplegics. Paraplegia 17: $163-168$.

6 O'Daniel WE, Hahn HR (1981) Follow-up usage of the Scott-Craig orthosis in paraplegia. Paraplegia 19: 373-378.

7 Engen T (1989) Lightweight modular orthosis. Prosthet Orthot Int 13: 125-129.

8 Brindley GS, Polkey CE, Rushton DN (1978-79) Electrical splinting of the knee in paraplegia. Paraplegia 16: $428-435$.

9 Marsolais EB, Kobetic R (1987) Functional electrical stimulation for walking in paraplegia. J Bone Joint Surg 69-A(5): 728-733.

10 Kralj AR, Bajd T (1989) Functional Electrical Stimulation: Standing and Walking After Spinal Cord Injury. CRC Press Inc, Boca Raton, Florida.

11 Rose GK (1979) The principles and practice of hip guidance articulations. Prosthet Orthot Int 3: 37-43.

12 Douglas R, Larson PF, D'ambrosia R, McCall RE (1983) The LSU Reciprocation-gait orthosis. Orthopedics 6(7): 834-839.

13 Rowley DI, Edwards J (1987) Helping the paraplegic to walk. J Bone Joint Surg 69-B(2): 173-174.

14 Patrick JH, McClelland MR (1985) Low energy cost reciprocal walking for the adult paraplegic. Paraplegia 23: 113-117.

15 Beckman J (1987) The Louisiana state university reciprocating gait orthosis. Physiotherapy 73(8): 386-392.

16 Isakov E, Mizrahi J, Najenson T (1986) Biomechanical and physiological evaluation of FES-activated paraplegic patients. J Rehabil Res Dev 23(3): 9-19.

17 Mizrahi J, Braun Z, Graupe D, Najenson T (1985) Quantitative gait and weight bearing evaluation of paraplegics using functional electrical stimulation. Med Biol Eng Comput 23: 106-107.

18 Fillauer C, Pritham CH, (1985) The development of a molded pelvic girdle and the pelvic casting fixture. Prosthet Orthot Int 38(4): 49-53.

19 Astrand PO, Rodhal K (1977) Textbook of Work Physiology. McGraw Hill, New York.

20 Waters RL, Lunsford BR, Perry J, Byrd R (1988) Energy-speed relationship of walking: standard tables. $J$ Orthop Res 6: 215-222.

21 Macgregor J (1981) The evaluation of patient performance using long-term ambulatory monitoring technique in the domiciliary environment. Physiotherapy 67(2): 30-33.

22 Butler P, Engelbrecht M, Major RE, Tait JH, Stallard J, Patrick JH (1984) Physiological cost index of walking for normal children and its use as an indicator of physical handicap. Dev Med Child Neurol 26: $607-612$.

23 Bar-on ZH, Nene AV (1990) Relationship between heart rate and oxygen uptake in thoracic level paraplegics. Paraplegia 28: 87-95.

24 Tomovic R, Vukobratovic M, Vodovnik L (1972) Hybrid actuators for orthotic systems - hybrid assistive system. In: Proceedings of International Symposium on External Control of Human Extremities. Dubrovnik, Yugoslavia: 73.

25 McClelland M, Andrew BJ, Patrick JH, Freeman PA, El Masri WS (1987) Augmentation of the Oswestry parawalker orthosis by means of surface electrical stimulation: gait analysis of three patients. Paraplegia 25: 32-38.

26 Bajd T, Bowman B (1982) Testing and modelling of spasticity. J Biomed Eng 4: 90-96.

26 Petrofsky JS, Phillipf CA, Larson P, Douglas R (1985) Computer synthesized walking: an application of orthosis and functional electrical stimulation (FES). J Neurol Orthop Med Surg 6(3): 219-230.

27 Phillips C (1989) Functional electrical stimulation and lower extremity bracing for ambulation exercise of the spinal cord injured individual: a medically prescribed system. Phys Ther 10: 842-849.

28 Phillips C, Petrofsky JS, Hendershot DM, Stafford D (1984) Functional electrical exercise. A comprehensive approach for physical conditioning of the spinal cord injured patient. Orthopedics 7(7): 1112-1123.

29 Katz RT, Green D, Sullivant T, Yarkony G (1987) Functional electric stimulation to enhance systemic fibrinolytic activity in spinal cord injury patients. Arch Phys Med Rehabil 68: 423-426. 